\title{
HSC/16/10
}

\section{Carbon pricing, forward risk premiums and pass-through rates in Australian electricity futures markets}

\author{
Paweł Maryniak ${ }^{1,2}$ \\ Stefan Trück ${ }^{3}$ \\ Rafał Weron ${ }^{1}$
}

${ }^{1}$ Department of Operations Research, Wrocław University of Technology, Poland

2 Department of Financial Investments and Risk Management, Wrocław University of Economics, Poland

${ }^{3}$ Faculty of Business and Economics, Macquarie University, Sydney, Australia

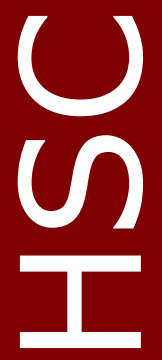

Hugo Steinhaus Center Wrocław University of Technology Wyb. Wyspiańskiego 27, 50-370 Wrocław, Poland http://www.im.pwr.wroc.pl/ hugo/ 


\title{
Carbon Premiums and Pass-Through Rates in Australian Electricity Futures Markets
}

\author{
Paweł Maryniak $^{\mathrm{a}, \mathrm{b}}$, Stefan Trück ${ }^{\mathrm{c}}$, Rafał Weron ${ }^{\mathrm{a}}$ \\ ${ }^{a}$ Department of Operations Research, Wrocław University of Technology, 50-370 Wrocław, Poland \\ ${ }^{b}$ Department of Financial Investments and Risk Management, Wroctaw University of Economics, \\ 53-345 Wroctaw, Poland \\ ${ }^{c}$ Centre for Financial Risk, Macquarie University, Sydney, NSW 2109, Australia
}

\begin{abstract}
We investigate the impacts of the carbon tax (effective July 2012 to July 2014) on wholesale electricity prices in the Australian National Electricity Market (NEM). Analyzing spot and futures contracts in four major regional markets, we first compute ex-ante forward risk premiums in the pre-tax period, then use them to derive market-implied carbon premiums and pass-through rates in the carbon tax and post-tax periods. We find that carbon premiums and pass-through rates became increasingly higher, once the Clean Energy Bill had been introduced and subsequently passed in 2011. We also find strong evidence for a quick reaction of the extracted carbon premiums to changes in opinion polls for the Australian federal election in 2013 and the decision to repeal the tax. During periods where market participants could be relatively certain that the tax would be effective, we find expected carbon pass-through rates between $65 \%$ and $140 \%$, which seem to be inversely related to emission intensities.
\end{abstract}

Keywords: Carbon Tax, Carbon Premium, Carbon Pass-Through Rate, Forward Risk Premium, Electricity Spot and Futures Prices

JEL: C51, C53, G13, Q41, Q58

\section{Introduction}

Australia's $\mathrm{CO}_{2}$ emissions levels are among the highest of all OECD countries (International Energy Agency, 2010). Hereby, stationary energy (including emissions from fuel consumption for electricity generation, fuels consumed for manufacturing, construction, commercial sectors and domestic heating) is the largest source of $\mathrm{CO}_{2}$ emissions in Australia. Electricity generation contributes by far the most to emissions in this sector with a share of close to $50 \%$ of all energy emissions, and approximately 35\% of all $\mathrm{CO}_{2}$ emissions in Australia (Australian Treasury, 2011). As a result of Australia's high $\mathrm{CO}_{2}$ emissions, in 2011 the Clean Energy Act as a package of legislation was introduced in order to reduce greenhouse gas emissions to 5\% below 2000 levels

Email addresses: pmaryniak@gmail . com (Paweł Maryniak), stef an.trueck@mq.edu .au (Stefan Trück), rafal.weron@pwr.edu.pl (Rafał Weron) 
by 2020 , and to $80 \%$ below 2000 levels by 2050. The Carbon Pricing Mechanism (CPM) was a central component of this Act with the aim to encourage Australia's largest emitters to enhance energy efficiency and invest in more sustainable and renewable energy. Under the CPM, all businesses emitting over 25,000 tonnes of carbon dioxide equivalent $\left(\mathrm{tCO}_{2} \mathrm{e}\right)$ emissions annually were required to purchase emissions units from the government (Clean Energy Regulator, 2013). The CPM became effective on 1 July 2012, with an introductory phase during which the price of uncapped permits was fixed: the initial price was determined to be 23 Australian dollars per tonne of carbon dioxide equivalent emissions $\left(\mathrm{AUD} / \mathrm{tCO}_{2} \mathrm{e}\right)$, increasing to 24.15 dollars from 1 July 2013 and to 25.40 dollars from 1 July 2014 to 30 June 2015. The original plan was then to have a transition to an Australian Emissions Trading Scheme (ETS) in July 2015 after the 3-year period of a fixed carbon price. However, after the election of a new government in September 2013, the Clean Energy Act, including the CPM and the carbon tax, was repealed by the Australian Senate on 17 July 2014.

Using futures data for four major regional markets within the Australian National Electricity Market (NEM), in this paper we investigate pass-through rates and the impact of the carbon tax on wholesale electricity prices. Following Nazifi (2016), we define the carbon pass-through rate as the ratio of change in the price of electricity to the change in marginal costs due to the carbon tax. Similarly, Nelson et al. (2012) and Huisman and Kilic (2015) define the carbon pass-through as the proportion of carbon prices passed through into electricity prices, which is effectively the proportion of higher costs incurred by consumers in the form of higher electricity prices attributable to the carbon tax.

We develop a framework that takes into account dynamic forward risk premiums in the futures markets, i.e., the relationship between quoted futures and expected spot prices during the delivery period, in order to extract the expected additional cost of the carbon tax for Australian wholesale electricity prices. Using futures prices instead of spot prices does not only allow us to take a forward-looking approach, but is also less sensitive to short-term events in electricity spot markets, such as extreme price spikes (Weron, 2006). This is of particular importance for the Australian NEM, where regional markets have been characterized as being among the most volatile and spikeprone in the world (Janczura et al., 2013; Clements et al., 2015; Ignatieva and Trück, 2016). Using futures instead of spot electricity prices, we also do not require detailed information on the actual fuel mix for the generation of electricity at each point in time to determine carbon pass-through rates. Instead we can derive directly market expectations on the impact of the introduction and abolishment of the tax on wholesale prices in the NEM. Finally, examining market reactions to key policy events such as the passing of the Clean Energy Act or the abolishment of the tax allows us to investigate how quickly market participants adapt to a changing regulatory environment.

\subsection{Literature Review}

So far, the relationship between carbon and energy prices as well as pass-through rates of carbon on electricity prices have mainly been studied for the European Union Emissions Trading Scheme (EU-ETS), see, e.g., Sijm et al. (2006), Hirschhausen and Zachmann (2008), Bunn and Fezzi (2009), Daskalakis and Markellos (2009), Fell (2010), Nazifi and Milunovich (2010), Blyth and Bunn (2011), Chevallier (2011), Gronwald et al. (2011), Sijm et al. (2012), Benth et al. (2013), Jouvet and Solier (2013), Nazifi (2013), Huisman and Kilic (2015) and Kanamura (2015, 
2016). Most of these studies find a significant impact of carbon prices on electricity markets in the European Union, and typically suggest pass-through rates ranging from $30 \%$ up to even more than $100 \%$ (Gulli and Chernyavska, 2013). Some of the cost pass-through to wholesale prices has often been characterized as 'windfall profits' to the electricity industry, since originally there was a free allocation of the permits to the sector in the EU-ETS (Sijm et al., 2006). Further, there is some evidence that pass-through rates vary over time and were significantly lower in 2009, after the global financial crisis (Jouvet and Solier, 2013; Huisman and Kilic, 2015).

While there have been a number of studies investigating the impact of the price of emission allowances on electricity prices in the European Union, the effects of the carbon tax on electricity prices in Australia have not been investigated by many authors. As pointed out by Nelson et al. (2012), a number of modeling and simulation studies on the potential impacts of introducing a carbon tax on electricity prices and broader economic impacts related to the introduction of an emission trading scheme have been conducted a few years before the actual tax was implemented. The analysis was undertaken mainly by leading Australian economic modeling firms using techniques such as linear programming, general equilibrium models or dynamic partial equilibrium analysis. These studies were rather inconsistent in their estimation of carbon pass-through rates and provide very different results, with rates ranging from 17\% McLennan Magasanik Associates (2008)), 100\% ROAM (2008), 128\% in the Garnaut (2008) report, up to more than 393\% (Simshauser and Doan, 2009), the latter reflecting a potential strategic and disruptive generator exit scenario.

Recently, there have also been a few empirical studies on the pass-through rate of the CPM on wholesale electricity prices in the Australian NEM. Nazifi (2016) investigates the interaction between a carbon price signal and wholesale electricity spot prices within the NEM. The author suggests that for the initial period of the carbon tax in Australia until October 2013, carbon costs were indeed fully passed on to wholesale electricity spot prices resulting in higher electricity prices for consumers and potential 'windfall profits' for some generators. Apergis and Lau (2015) examine the role of climate policy uncertainties in the Australian electricity market and suggest that the NEM can be described as a less stable electricity market in comparison to other electricity markets around the world. They suggest that in the NEM also a relatively high degree of market power is exercised by generators across regional markets. This might have significant consequences for the effectiveness of carbon dioxide mitigating policies, especially, when there is uncertainty as to whether the planned environmental policy is put in place for the lifespan of undertaken investments. O'Gorman and Jotzo (2014) investigate the impact of the carbon tax on electricity demand, supply and emissions. They find that during the period when the tax was in place electricity demand in the NEM declined by $3.8 \%$, while the emissions intensity of electricity supply was reduced by almost $5 \%$. The authors also suggest that the carbon price markedly changed relative costs between different types of power plants, leading to emissions-intensive generators such as brown coal and black coal reducing their output. They conclude that the carbon tax has worked as expected in terms of its short-term impacts, while its effect on investment in power generation assets has probably been limited, due to political uncertainty about the continuation of the carbon pricing mechanism. 


\subsection{Our Contribution}

Our study contributes to the literature in several dimensions. Firstly, we extend the relatively sparse literature on the impact of the Australian CPM on wholesale electricity prices by conducting an extensive empirical analysis of forward premiums in the extremely volatile and so far unexplored (from this point of view) Australian electricity market. To the best of our knowledge, we also provide a pioneering analysis of pass-through rates of the tax on electricity futures prices in the NEM. While few studies have focused on carbon pass-through rates on spot electricity prices in Australia, so far there is no work that measures and quantifies the impact of the carbon tax on expectations and risk premiums in electricity derivative markets.

Secondly, we develop a framework that allows us to take into account existing forward risk premiums in electricity futures markets in order to appropriately estimate carbon pass-through rates. Further, using futures prices instead of spot prices allows us to take a forward-looking approach, and to thoroughly examine the impact of key policy events on observed carbon premiums in the electricity markets. Hereby, we analyze the impact of announcements about the introduction of the tax, opinion polls on upcoming federal election, as well as the actual change of the federal government that was accompanied by the promise to repeal the tax.

Finally, we examine carbon pass-through rates over a long sample that includes the period before the carbon tax became effective, the period of its lifetime from July 2012 to June 2014 as well as the period after the tax had been repealed. While previous studies in the Australian context were either entirely based on simulation results (McLennan Magasanik Associates, 2008; ROAM, 2008; Simshauser and Doan, 2009) or restricted to spot prices from shorter periods (O'Gorman and Jotzo, 2014, Nazifi, 2016), we examine a significantly longer time period of spot and futures prices that will allow us to gain additional insights on the impact of the introduction and abolishment of the tax on wholesale electricity prices in Australia.

\section{Risk Premiums in Electricity Futures Markets}

Due to the non-storability of electricity as a commodity, the literature usually suggests a theory that considers equilibrium in expectations, and risk aversion amongst agents with heterogeneous requirements for hedging the uncertainty of future spot prices (Bessembinder and Lemmon, 2002). Using this approach, electricity forward and derivative prices can be determined as the expected spot price plus an ex-ante forward risk premium (Longstaff and Wang, 2004; Weron, 2008; Redl et al., 2009; Botterud et al., 2010; Bunn and Chen, 2013; Handika and Trück, 2014b); the latter typically interpreted as compensation for bearing the spot price risk. Hence, in electricity markets, the relationship between the observed price for a futures contract at time $t$ referring to the delivery of electricity over the period $\left[T_{1}, T_{2}\right]$, i.e., $F_{t,\left[T_{1}, T_{2}\right]}$, and the expected at time $t$ average spot price over the period $\left[T_{1}, T_{2}\right]$, i.e., $\mathbb{E}_{t}\left(\bar{S}_{\left[T_{1}, T_{2}\right]}\right)$, can be formally written as:

$$
F_{t,\left[T_{1}, T_{2}\right]}=\mathbb{E}_{t}\left(\bar{S}_{\left[T_{1}, T_{2}\right]}\right)+\pi_{t,\left[T_{1}, T_{2}\right]}
$$

where $\pi_{t,\left[T_{1}, T_{2}\right]}$ is the forward risk premium or simply forward premium $]^{1}$

1 Note that some authors (see e.g. Benth et al., 2008, 2013; Haugom and Ullrich, 2012, Haugom et al., 2014) use the term risk premium to denote $\pi_{t,\left[T_{1}, T_{2}\right]}$. This is confusing since the risk premium is typically defined as the negative of 


\subsection{Literature on Ex-post Premiums}

Empirical studies on the existence of forward risk premiums in electricity futures markets do not provide clear-cut results and have been mainly conducted for realized (or ex-post) premiums. Comparing day-ahead ('forward') and real-time ('spot') prices, Longstaff and Wang (2004) and more recently Haugom and Ullrich (2012) examine whether the realized premiums paid in the PJM electricity market are significant. They conclude that these very short-term forward premiums are generally positive, but their significance decreases over the years. Redl et al. (2009) find positive ex-post premiums for month-ahead futures contracts in the Nord Pool and EEX markets. They report premiums ranging from $8 \%$ for considered base load contracts in the Nord Pool market and $9 \%$ for base load and $13 \%$ for peak load contracts in the EEX market.

Botterud et al. (2010) find positive on average ex-post risk premiums (hence negative forward premiums) in the Nord Pool Asian options and futures prices, but in more recent studies Haugom et al.(2014) and Weron and Zator (2014) report that ex-post premiums vary significantly over time. For Australia, so far only two studies have investigated the existence of premiums in electricity futures contracts (Handika and Trück, 2014a b), suggesting typically positive and also relatively high ex-post forward premiums in most of the regional markets.

\subsection{Literature on Ex-ante Premiums}

The few existing studies on ex-ante premiums in electricity markets are also not conclusive. Considering only one time point (30 September 2003) and three stochastic models for the spot price (a jump-diffusion and two regime-switching models), Bierbrauer et al. (2007) conclude that futures prices in the German EEX market are generally greater than the expected future spot (i.e., the forward premium is positive in the short term) for the first six months and less than the expected spot (i.e., the forward premium is negative) for the second, third and fourth quarter in 2004 . In a related study on forward premiums in the EEX market, Benth et al. (2008) propose a framework that explains how the premium depends on the risk preferences of market players. They argue that long-term contracts will be mainly used by producers to hedge their future electricity production, who may be willing to accept prices lower than the actual expected spot prices in order to guarantee sales ( $\rightarrow$ a negative long-term forward premium). On the other hand, in the short-term, retailers or consumers, aiming to hedge the risk of extreme price outcomes in the spot market, may be willing to pay an additional premium for their hedge ( $\rightarrow$ a positive short-term forward premium). The authors support their conjectures with a limited empirical study involving three time points (1 January 2002, 3 March 2003, 4 October 2005), monthly, quarterly and yearly EEX futures contracts and a jump-diffusion model for the spot price.

On the other hand, quite contradictory results are reported by Weron $(2008)$ for the Nord Pool market. Studying a selection of so-called block contracts (i.e., futures with four week delivery periods) in the 3-year period from Spring 1998 to Spring 2001 and using a jump-diffusion model, the author finds that for most of the time the forward premium is positive and increasing with time to maturity. $2^{2}$ Weron (2008) further argues that the positive forward premium can be explained by

the forward premium, i.e., the difference between the expected spot price and the forward price (for a discussion see Weron and Zator. 2014).

2 Note that Weron (2008) presents the results in terms of the risk premium, i.e., the negative of the forward premium defined by (1), hence the 'opposite' conclusions. 
a higher incentive for hedging on the demand side relative to the supply side, because of the nonstorability of electricity as compared to the (limited and costly but still existent) storage capabilities of water and fossil fuels.

\subsection{The Carbon Premium}

Our study is not only concerned with the analysis of forward premiums in the NEM, but has a specific focus on the effects of the CPM on observed futures prices. Clearly, news about the introduction or abolishment of the carbon tax will have a strong impact on these prices. Thus, for periods that are affected by the carbon tax (or expectations about the tax), an appropriate model for the relationship between futures prices and expected future spot prices should also incorporate a term reflecting the (expected) price increase as a result of the carbon tax during the relevant periods.

Therefore, for periods that are affected by the carbon tax, we consider the following modification of Eqn. (1):

$$
F_{t,\left[T_{1}, T_{2}\right]}=\mathbb{E}_{t}\left(\bar{S}_{\left[T_{1}, T_{2}\right]}\right)+\underbrace{\pi_{t,\left[T_{1}, T_{2}\right]}^{F}+\pi_{t\left[T_{1}, T_{2}\right]}^{C}}_{\text {(aggregate) forward premium }},
$$

where the (aggregate) forward premium is composed of:

- $\pi_{t,\left[T_{1}, T_{2}\right]}^{F}$ - the 'pure' forward premium, which can be regarded as a non-carbon tax related component of the (aggregate) forward premium, equivalent to $\pi_{t,\left[T_{1}, T_{2}\right]}$ from Eqn. (1) for periods not affected by the carbon tax,

- $\pi_{t,\left[T_{1}, T_{2}\right]}^{C}$ - the carbon premium, which reflects the actual dollar amount as a fraction of observed futures prices that can be attributed to the carbon tax.

Note that for Eqn. (2) to hold, we have to assume that we are able to disentangle the carbon premium from the 'pure' forward premium, i.e., assume that the two do not overlap (at least not significantly) and that $\pi_{t,\left[T_{1}, T_{2}\right]}^{F}$ is not affected by news about the introduction or abolishment of the CPM.

Based on the relationship suggested in Eqn. (2), the carbon premium can then be calculated as:

$$
\pi_{t,\left[T_{1}, T_{2}\right]}^{C}=F_{t,\left[T_{1}, T_{2}\right]}-\left[\mathbb{E}_{t}\left(\bar{S}_{\left[T_{1}, T_{2}\right]}\right)+\pi_{t,\left[T_{1}, T_{2}\right]}^{F}\right],
$$

where the term in the square brackets is an estimate of the futures price in a business-as-usual (no carbon tax) scenario. Unfortunately this term is not directly observable. Therefore, to extract the carbon premium implied in futures prices, we require an appropriate estimate for the expected spot price under a business-as-usual scenario as well as an estimate for the 'pure' forward premium. In Section 3 we will lay out in more detail how these estimates can be obtained.

Note also, that ultimately we are interested in comparing the extracted carbon premium to the emission intensity adjusted additional cost of electricity prices. The latter is simply the (expected) average emission intensity of electricity generation multiplied by the price of the tax per ton of $\mathrm{CO}_{2}$, i.e., $\mathbb{E}_{t}\left(E I_{\left[T_{1}, T_{2}\right]}\right) \times C T_{\left[T_{1}, T_{2}\right]}$. 


\section{The Econometric Framework}

Using futures data on the Australian National Electricity Market (NEM) for the four major regional markets (NSW, QLD, SA and VIC), we aim to investigate carbon pass-through costs on wholesale electricity prices in a forward looking manner. Recall that the carbon tax became effective on 1 July 2012, with an intended introductory phase until 30 June 2015) during which the price of uncapped permits was fixed: first at $23 \mathrm{AUD} / \mathrm{tCO}_{2} \mathrm{e}$, then from 1 July 2013 at 24.15 $\mathrm{AUD} / \mathrm{tCO}_{2} \mathrm{e}$ and from 1 July 2014 at $25.40 \mathrm{AUD} / \mathrm{tCO}_{2} \mathrm{e}$. After the election of a new government, the carbon tax was repealed by the Australian Senate on 17 July 2014. Based on the introduction and later abolishment of the tax, we therefore have three periods of particular interest for this study:

1. the sample period when the tax was not around yet, but futures prices for periods referring to the carbon tax period were already available (before July 2012),

2. the sample period referring to the years when the tax was effective, while due to the political climate (upcoming elections with abolishment of the CPM as a key promise of the opposition) there was uncertainty among market participants about how long the tax would be in place (July 2012 - September 2013),

3. and the period when the tax was still effective, but when it became clear that the tax would be abolished in the near future (after September 2013, before July 2014).

Note that for the latter case, we will investigate the pass-through costs for periods referring to the remaining tax period (Q4 2013, Q1 and Q2 2014) as well as for the post-tax period (from Q3 2014 onward).

\subsection{Models for the Electricity Spot Price}

\subsubsection{Dealing with Seasonality}

As Janczura et al. (2013) argue, the first crucial step in defining a model for electricity spot price dynamics consists of finding an appropriate description of the seasonal pattern. The standard approach to seasonal decomposition splits the series under investigation into the trend-cycle or long-term seasonal component (LTSC; $L_{t}$ ), the periodic short-term seasonal component (STSC; $s_{t}$ ) and remaining variability (i.e. the stochastic component; $X_{t}$ ), either in an additive or a multiplicative fashion. Since our goal here is to analyze the prices of quarterly futures contracts, we ignore the short-term periodicities and consider only the LTSC.

In an extensive study on the estimation and forecasting of the LTSC, Nowotarski et al. (2013) considered a battery of over 300 models. They found that the wavelet-based models were not only better in extracting the LTSC from a series of spot electricity prices but also significantly better in terms of forecasting these prices up to a year ahead than piecewise constant or sinusoidal functions. In a follow up study, Weron and Zator (2015) raised the issue of numerical complexity of the wavelet-based technique and advocated the Hodrick and Prescott (1997) filter as a simpler, yet equally flexible alternative to wavelet smoothing. In an independent study, Lisi and Nan (2014) found it to be a very well performing smoother as well.

Following the latter advice, we have focused on two classes of well-performing LTSC models: wavelet-based and Hodrick-Prescott (HP) filter-based. We have found that the latter turned out be a 
more robust and a better-behaving model for the considered Australian electricity spot prices, both in- and out-of-sample, and selected it as the only specification of the trend-seasonal component in this paper. Recall, that for a noisy (or volatile) input series $y_{t}$, the HP filter returns a smoothed series $L_{t}$ which minimizes:

$$
\min _{L_{t}}\left\{\sum_{t=1}^{T}\left(y_{t}-L_{t}\right)^{2}+\lambda \sum_{t=2}^{T-1}\left[\left(L_{t+1}-L_{t}\right)-\left(L_{t}-L_{t-1}\right)\right]^{2}\right\},
$$

where $T$ is the number of observations (in this study: $1095 \times 24=26280$ hours of the 3-year calibration window) and $\lambda$ is a smoothing parameter.

Since the Australian electricity spot prices are extremely volatile, we use a spike damping transformation to preprocess the spot prices beforehand. For a series of spot prices $P_{t}$, the transform yields series:

$$
y_{t}= \begin{cases}\log \left(P_{t}+1-\eta\right), & \text { for } P_{t} \geq \eta, \\ -\log \left(\eta+1-P_{t}\right), & \text { for } P_{t}<\eta,\end{cases}
$$

where $\eta$ is the median of $P_{t}$. This transformation is an alternative to the commonly used logarithmic transformation, which dampens spikes (a wanted feature) but unnecessarily pronounces price drops for prices below the 'normal' level (thus distorting the scale). The transform defined by (5), on the other hand, has a symmetric impact on prices below and above $\eta$. Such a transformation makes the observations in the 'normal' price regime the most significant for estimation of the LTSC.

\subsubsection{Modeling the Stochastic Behavior of Spot Electricity Prices}

For modeling the stochastic nature of spot electricity prices, we utilize the class of Markov regime-switching (MRS) processes. This class can be considered as being more appropriate than jump-diffusion models, since MRS models admit spike clustering, a feature observed for electricity spot prices on the hourly as well as the daily time scale (for a discussion see Weron, 2014).

The idea underlying MRS models is to represent the (deseasonalized and detrended) spot price process $X_{t}$ by a collection of $J$ states or regimes with different underlying stochastic processes $X_{t, j}, j=1,2, \ldots, J$. The switching mechanism between the states is assumed to be an unobserved (latent) Markov chain $R_{t}$ governed by a transition matrix containing the probabilities $p_{i j}=P\left(R_{t+1}=j \mid R_{t}=i\right)$ of switching from regime $i$ at time $t$ to regime $j$ at time $t+1$. Because of the Markov property the current state $R_{t}$ at time $t$ depends on the past only through the most recent value $R_{t-1}$. In general, multi-regime models can be considered, but two or three regimes are typically enough to adequately model the dynamics of electricity spot prices (Janczura and Weron. 2010; Karakatsani and Bunn, 2010). Indeed, two-regime MRS models provide a reasonable fit to log-prices in the regional NSW, QLD, SA and VIC markets and we use them in the empirical part of the paper. Moreover, we apply a specification popular in the energy economics literature where the individual regimes are driven by independent processes (Bierbrauer et al., 2007; Eichler and Türk, 2013; Janczura et al., 2013; Liebl, 2013; Janczura, 2014; Weron, 2014).

In this approach, the first or base regime $\left(R_{t}=1\right)$ describes the 'normal' price behavior and is 
given by a mean-reverting process. In discrete time, the process can be written as

$$
X_{t, 1}=\alpha_{1}+\left(1-\beta_{1}\right) X_{t-1,1}+\sigma_{1} \epsilon_{t}
$$

where $\epsilon_{t}$ is standard i.i.d. Gaussian noise. The second regime $\left(R_{t}=2\right)$ then represents the sudden price spikes caused by unexpected supply shortages and is given by i.i.d. random variables from the shifted log-normal distribution:

$$
\log \left(X_{t, 2}-q_{2}\right) \sim \mathrm{N}\left(\mu_{2}, \sigma_{2}^{2}\right), \quad X_{t, 2}>q_{2} .
$$

In general, $q_{2}$ can be numerically optimized (see e.g. Weron, 2014), but here it is set to the median of the dataset. Such a specification of the spike regime distribution ensures that the observations below the median will not be classified as spikes.

Calibration of MRS models is not straightforward, since the state process is latent and not directly observable. We have to infer the parameters and state process values at the same time. In this paper we use a variant of the Expectation-Maximization (EM) algorithm, optimized for MRS structures with independent regimes by Janczura and Weron (2012). $3^{3}$

\subsubsection{Forecasting the Seasonal Components and Spot Electricity Prices}

As discussed in Section 3.1.1, in this paper we use the Hodrick and Prescott (1997) filter for modeling the LTSC. Like a wavelet-based filter or other non- or semiparametric smoothers, the HP filter is able to provide a good in-sample fit, but its use for forecasting is limited. To extrapolate the output of the HP filter-based LTSC we use the well performing 'exponential decay to the median' method of Nowotarski et al. (2013). Within this approach the 1095-day calibration window is first extended one year forward by connecting the last day of the calibration period (on the time axis) and the current spot price (on the price axis) with a time point 365 days into the future (on the time axis; observation no. 1460) and the median of the spot prices in the calibration window (on the price axis), using an exponentially decaying deterministic function with a 180-day mean lifetime of the decay (i.e., a decay factor of $\frac{1}{180}$ ). Since in this study we require spot price forecasts for up to four years ahead, we further extend the exponentially decaying function for the following three years (at the level of the median of the spot prices in the 3-year calibration window).

Next, we apply a HP filter with smoothing parameter $\lambda=10^{5}$ to all $2555(=1095+4 \cdot 365)$ observations. The values of the HP smoother for observations no. 1096, 1097, ., 2555 are taken as the 4-year forecast of the LTSC (for an illustration see Figs. 3 and 4 in Nowotarski et al., 2013)..$^{4}$ Finally, we simulate 10,000 trajectories of the MRS model fitted to the 3-year calibration window ('forecasts' of the stochastic component) and add them to the forecasts of the LTSC to yield 10,000 simulated trajectories of the spot price. The latter are used to obtain the expected at time $t$ average spot price over the delivery period $\left[T_{1}, T_{2}\right]$, i.e., $\mathbb{E}_{t}\left(\bar{S}_{\left[T_{1}, T_{2}\right]}\right)$.

3 The Matlab codes for estimating (mrs2ir_est.m) and simulating (mrs2ir_sim.m) independent regime MRS models is available from the HSC RePEc repository at https://ideas.repec.org/s/wuu/hscode.html

4 The Matlab code for estimating and forecasting the LTSC using wavelets combined with the "exponential decay to the median' method (ltscwave.m) is available from the same HSC RePEc repository. 
Table 1: Descriptive statistics for electricity spot prices (in AUD/MWh) in NSW, QLD, SA, and VIC, for the entire sample period (upper panel), the considered period before the carbon tax (second panel), the carbon tax period (third panel), and the considered sample period after the carbon tax (bottom panel).

\begin{tabular}{|c|c|c|c|c|c|c|c|}
\hline \multicolumn{8}{|c|}{ Entire Sample Period (1 January 2010 - 31 December $2015 ; N=2191$ days) } \\
\hline Market & Mean & Median & Maximum & Minimum & Std. Dev. & Skewness & Kurtosis \\
\hline NSW & 41.45 & 35.01 & 1282.01 & 17.36 & 44.36 & 20.07 & 512.67 \\
\hline QLD & 45.78 & 33.44 & 1885.87 & -13.98 & 73.79 & 15.84 & 323.66 \\
\hline SA & 48.55 & 37.03 & 2347.72 & -103.16 & 81.21 & 18.61 & 445.46 \\
\hline VIC & 39.43 & 33.20 & 1276.90 & -4.89 & 46.64 & 17.88 & 409.92 \\
\hline \multicolumn{8}{|c|}{ Pre Carbon Tax Period (1 January 2010 - 30 June 2012; $N=912$ days) } \\
\hline NSW & 33.77 & 27.02 & 1282.01 & 17.36 & 64.50 & 15.61 & 280.33 \\
\hline QLD & 30.14 & 24.99 & 1062.37 & -13.98 & 53.28 & 15.43 & 260.01 \\
\hline SA & 36.51 & 27.35 & 2347.72 & -103.16 & 113.24 & 16.09 & 286.19 \\
\hline VIC & 31.15 & 25.70 & 1276.90 & -4.89 & 62.43 & 16.23 & 295.76 \\
\hline \multicolumn{8}{|c|}{ Carbon Tax Period ( 1 July $2012-30$ June $2014 ; N=730$ days) } \\
\hline NSW & 53.68 & 51.84 & 303.12 & 44.32 & 11.26 & 15.52 & 332.44 \\
\hline QLD & 62.72 & 53.76 & 585.63 & 0.81 & 42.28 & 8.18 & 87.32 \\
\hline SA & 65.73 & 54.57 & 806.26 & 31.93 & 50.63 & 8.45 & 98.92 \\
\hline VIC & 54.46 & 49.37 & 722.65 & 36.95 & 34.95 & 13.42 & 224.06 \\
\hline \multicolumn{8}{|c|}{ Post Carbon Tax Period (1 July $2014-31$ December $2015 ; N=549$ days) } \\
\hline NSW & 37.94 & 35.01 & 472.77 & 19.24 & 21.65 & 15.40 & 299.35 \\
\hline QLD & 49.25 & 33.67 & 1885.87 & 2.75 & 117.72 & 12.65 & 178.72 \\
\hline SA & 45.69 & 36.92 & 259.59 & -5.82 & 31.37 & 3.14 & 16.74 \\
\hline VIC & 33.18 & 31.97 & 160.94 & 11.63 & 11.62 & 3.20 & 30.63 \\
\hline
\end{tabular}

\section{Empirical Results}

\subsection{The Data}

Half-hourly data on spot electricity prices and emission intensities is available from the Australian Energy Market Operator (AEMO). We consider average daily values for our analysis and the calibration of the models. Daily quotations of futures prices for quarterly base load contracts for New South Wales (NSW), Queensland (QLD), South Australia (SA) and Victoria (VIC) are obtained from ASX Energy $\left.\right|^{5}$

In Table 1 we provide descriptive statistics for spot electricity prices for all four regional markets and the time period from 1 January 2010 to 31 December 2015. The substantial price increase during the carbon tax period from (1 July 2012 - 30 June 2014) is clearly visible. This can also be seen in Figure 1 where we plot daily spot electricity prices for NSW and VIC for the entire sample period. The figure illustrates the typical extreme variation in spot electricity prices as well as a number of substantial price spikes. Note that for the purpose of illustration, in Figure 1 prices were capped at $\$ 200$, while actually for both markets there were a number of occasions where average daily prices exceeded $\$ 1000$ and half-hourly prices even reached the market price cap

5 See https://asxenergy.com.au/. 
Table 2: Descriptive statistics for emission intensities (in $\mathrm{tCO}_{2} \mathrm{e} / \mathrm{MWh}$ ) in NSW, QLD, SA and VIC. Like in Table 1 . the results are presented separately for the entire sample period (1 January 2010 - 31 December 2015), the considered period before the carbon tax (1 January 2010 - 30 June 2012), the carbon tax period (1 July 2012 - 30 June 2014), and the considered sample period after the carbon tax (1 July 2014-31 December 2015).

\begin{tabular}{lcccccccc}
\hline & \multicolumn{2}{c}{ Entire Period } & \multicolumn{2}{c}{ Pre-Tax Period } & \multicolumn{2}{c}{ Carbon Tax Period } & \multicolumn{2}{c}{ Post-Tax Period } \\
\hline & Mean & Std. Dev. & Mean & Std Dev. & Mean & Std Dev. & Mean & Std Dev. \\
\hline NSW & 0.9238 & 0.0339 & 0.9342 & 0.0296 & 0.9058 & 0.0336 & 0.9305 & 0.0310 \\
QLD & 0.8336 & 0.0244 & 0.8272 & 0.0154 & 0.8300 & 0.0192 & 0.8492 & 0.0341 \\
SA & 0.5497 & 0.1313 & 0.6106 & 0.1062 & 0.5028 & 0.1183 & 0.5110 & 0.1448 \\
VIC & 1.2078 & 0.0654 & 1.2420 & 0.0553 & 1.1746 & 0.0614 & 1.1950 & 0.0583 \\
\hline
\end{tabular}

that was $\$ 12,500$ for the $2010-11$ and $2011-12$ financial years, $\$ 12,900$ for $2012-13, \$ 13,100$ for 2013-2014, $\$ 13,500$ for 2014-2015, and $\$ 13,800$ for the 2015-16 financial year. ${ }^{6}$

In Figure 2 we plot the emission intensities for the sample period for NSW and VIC. In particular for VIC, we observe a reduced level of emission intensities that has also been pointed out by O'Gorman and Jotzo (2014). Table 2 provides additional information. We find that for all markets, apart from QLD, emission intensities were reduced during the carbon tax period in comparison to the pre-tax period. Overall, we observe a reduction of approximately $3.0 \%$ for NSW, $17.7 \%$ for SA and $5.4 \%$ for VIC. For the period after the abolishment of the tax, emission intensities increased but remained lower than during the pre-tax period in VIC, reverted back almost to their pre-tax levels in NSW and to an even higher level in QLD. Due to the substantial increase of renewable energy generation in SA, emission intensities remained at a relatively low level of 0.51 $\mathrm{tCO}_{2} \mathrm{e} / \mathrm{MWh}$ also for the post-tax period.

\subsection{Ex-ante Forward Premiums in the Pre-carbon Tax Period}

In a next step, we use quarterly futures contracts from 1 April 2008 to 31 March 2011 to determine ex-ante forward premiums in the time period before the introduction of the carbon tax, by solving Eqn. (1) for $\pi_{t,\left[T_{1}, T_{2}\right]}$ or equivalently by solving Eqn. (2) for $\pi_{t,\left[T_{1}, T_{2}\right]}^{F}$ conditioned on $\pi_{t,\left[T_{1}, T_{2}\right]}^{C}=0$. We estimate the premiums for each of the quarters and regional markets separately. Note that we calculate ex-ante forward premiums at different times to delivery based on monthly median estimates of these premiums for futures contracts quoted between 1 April 2008 and 31 March 2011. The choice of the latter time interval is not arbitrary. On one hand, it is driven by the desire to use as recent data as possible (hence the lower limit of April 2008), on the other, the restriction not to use data from the period when the carbon tax was effective or very likely to become effective in the near future (hence the upper limit of March 2011; the final version of the Clean Energy Bill was released by the Labor government on 10 July 2011). For example, the exante premium for the NSW Q1 contract 12 months prior to delivery is determined as the median of the estimated ex-ante premiums for three 12 months to delivery Q1 contracts: Q1 2010 quoted for all business days in January 2009, Q1 2011 quoted in January 2010, and Q1 2012 quoted in

6 Note that unless stated otherwise all monetary values refer to Australian dollars per megawatt hour (AUD/MWh), but for brevity are represented by the dollar symbol $(\$)$. 


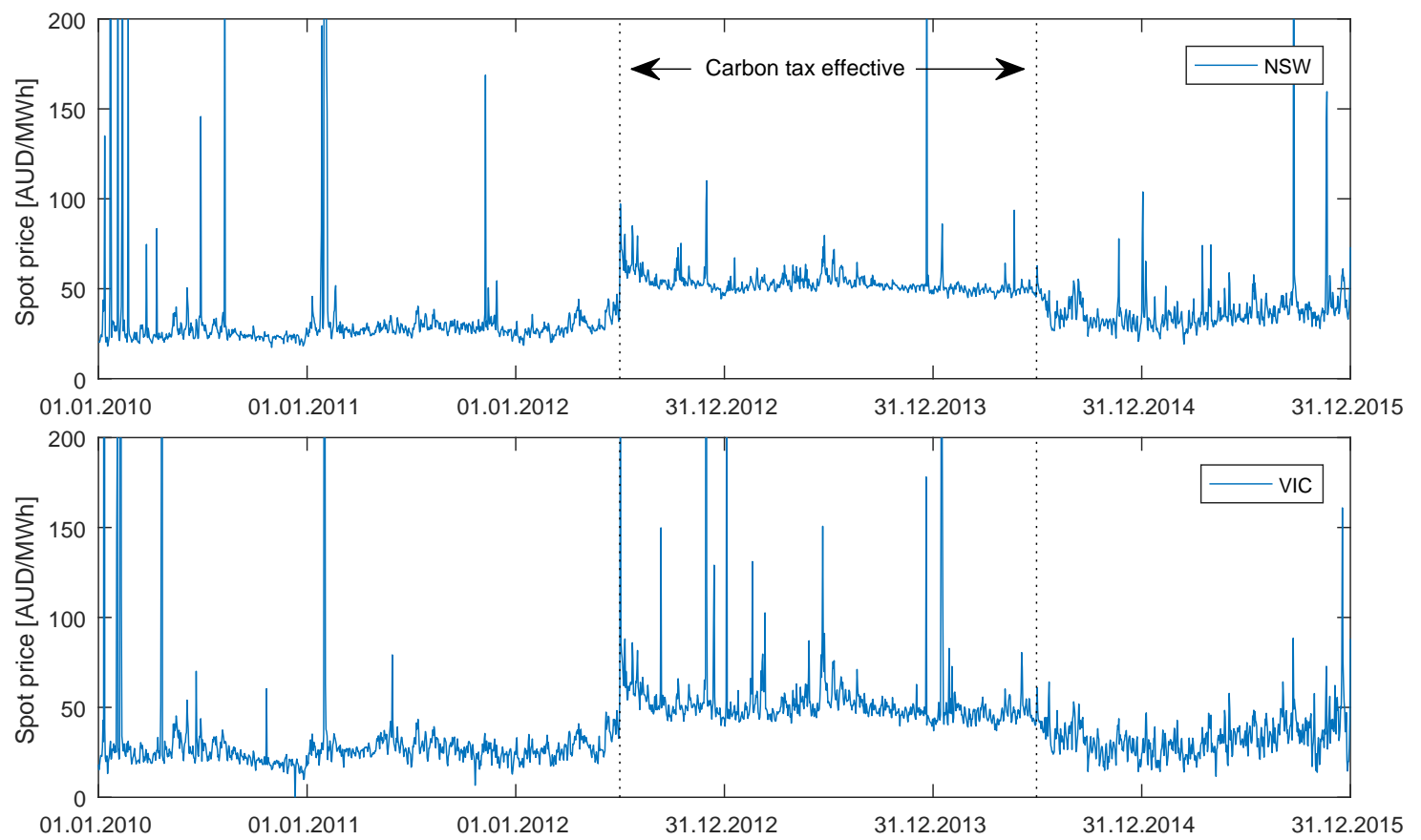

Figure 1: Daily spot electricity prices from 1 January 2010 to 31 December 2014 for NSW (upper panel) and VIC (lower panel). Note that for the purpose of illustrating the price shift due to the introduction of the carbon tax, prices were capped at $\$ 200$. The dotted vertical lines indicate the period when the carbon tax was effective, i.e., from 1 July 2012 to 30 June 2014.

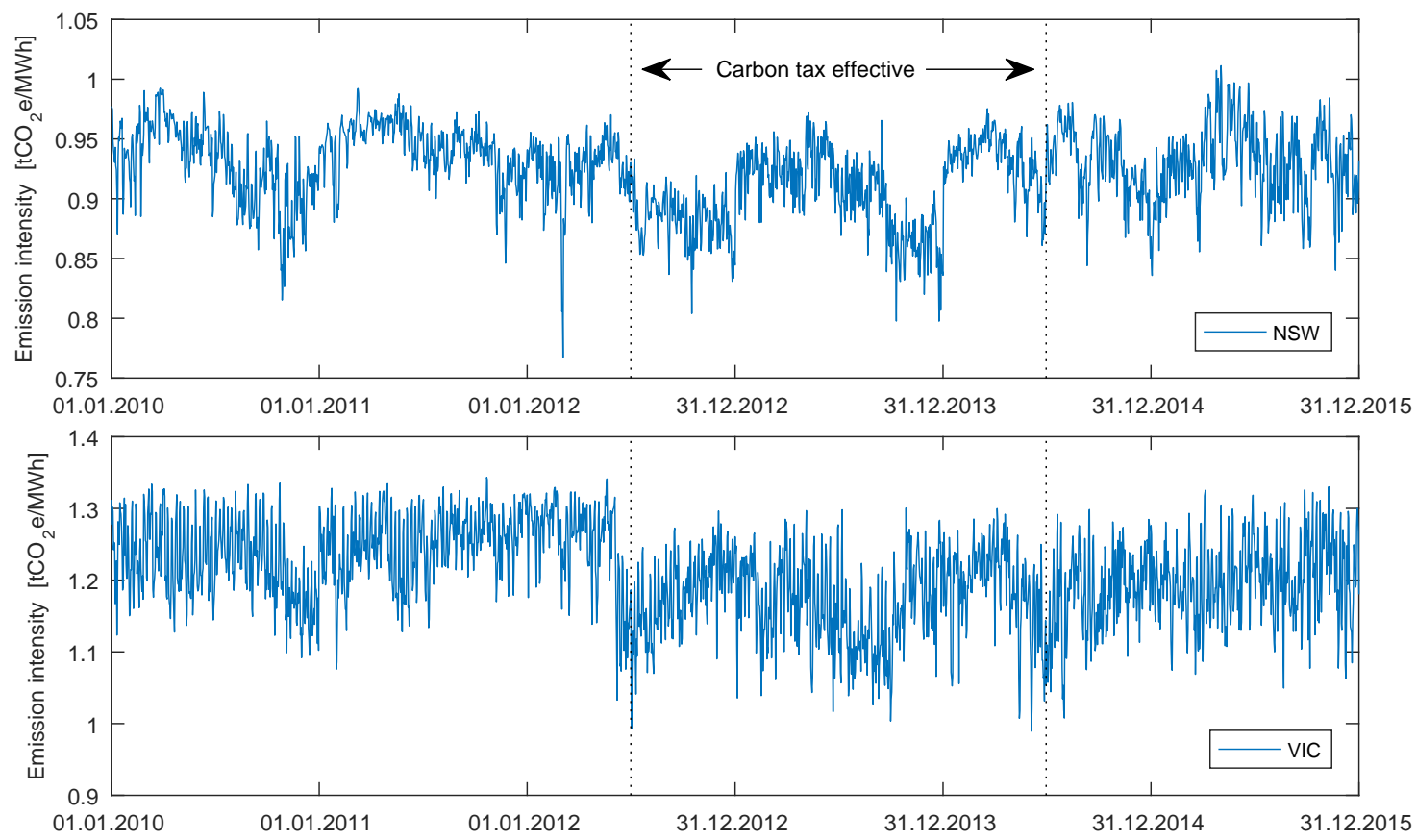

Figure 2: Daily emission intensities from 1 January 2010 to 31 December 2015 for NSW (upper panel) and VIC (lower panel). The dotted vertical lines indicate the period when the carbon tax was effective, i.e., from 1 July 2012 to 30 June 2014. 
Table 3: Emission intensities per MWh during the two financial years from June 2010 to July 2012 for each regional market and expected additional cost of electricity generation based on the introduced carbon tax.

\begin{tabular}{lcccc}
\hline Market & $\begin{array}{c}\text { Emission Intensity } \\
\text { per MWh }\end{array}$ & $\begin{array}{c}\text { Cost 2012-2013 } \\
\text { in AUD/MWh }\end{array}$ & $\begin{array}{c}\text { Cost 2013-2014 } \\
\text { in AUD/MWh }\end{array}$ & $\begin{array}{c}\text { Cost 2014-2015 } \\
\text { in AUD/MWh }\end{array}$ \\
\hline NSW & 0.944 & 21.71 & 22.80 & 23.98 \\
QLD & 0.836 & 19.23 & 20.19 & 21.23 \\
SA & 0.630 & 14.49 & 15.21 & 16.00 \\
VIC & 1.246 & 28.66 & 30.09 & 31.65 \\
\hline
\end{tabular}

January 2011. Note that we are using a monthly time grid, whereby all days in January are 12 months 'prior to delivery' in Q1 of the next year and all days in December are 1 month 'prior to delivery'. To eliminate noise in the term structure of the forward premiums we smooth the estimated premiums with a Hodrick and Prescott (1997) filter.

In Figure 3 we plot the estimated ex-ante forward premiums for the different quarterly contracts (Q1, Q2, Q3 and Q4) for NSW, while in Figure 4 the premiums for VIC. The vertical bars indicate the interquartile (IQR) range for each month-to-maturity, i.e., the interval spanned by the 25 th and 75th percentiles of the premium distribution for a given month. Clearly, the obtained term structures of the forward premiums are increasing with time to maturity. More specifically, for the first 12-18 months-to-maturity the premiums are close to zero for all quarters but Q1, then they increase to \$10-15 for distant maturities (third and fourth year). For Q1, the shape is similar but the premiums are much higher - ca. \$10-20 for the first 12-18 months-to-maturity and ca. \$45-55 for 30-46 months-to-maturity. These results resemble the findings of Weron (2008) for the Nord Pool market, but contradict the results of Bierbrauer et al. (2007) and Benth et al. (2008) for the German EEX market where the term structure was rather downward sloping with time to maturity. Apparently, the forward premium may exhibit different dynamics depending on the characteristics of the market (as noted by Huisman and Kilic, 2012) and the behavior of market participants.

\subsection{Carbon Premiums}

We now compare the futures implied carbon pass-through costs to an expected price increase based on emission intensities for the four markets. In Table 3 we provide information on emission intensities per MWh of electricity generation for the two financial years from June 2010 to July 2012 (the two years preceding the carbon tax) for each of the regional markets as well as the expected additional costs of electricity generation based on the tax. Recall, that the price of carbon was determined to be $\$ 23$ for the period 1 July 2012 - 30 June 2013, $\$ 24.15$ for the period 1 July 2013 - 30 June 2014 and $\$ 25.40$ for the period 1 July 2014 - 30 June 2015. We find that in particular for VIC quite dramatic increases by more than $\$ 30$ in the costs of electricity generation could be expected due to the tax. Also for NSW and QLD the additional costs are above \$20.

After estimating in Section 4.2 historical ex-ante forward premiums using Eqn. (1), i.e., in the pre-carbon tax period, we now apply Eqn. (3) to extract the carbon premiums in the periods when the carbon tax was in place or was likely to become effective. Recall from Section 2.3 that we implicitly assume that the 'pure' forward premium $\pi_{t,\left[T_{1}, T_{2}\right]}^{F}$ remains unaffected by the introduction of the carbon tax and all uncertainty related to the carbon tax gets 'transferred' to the carbon 

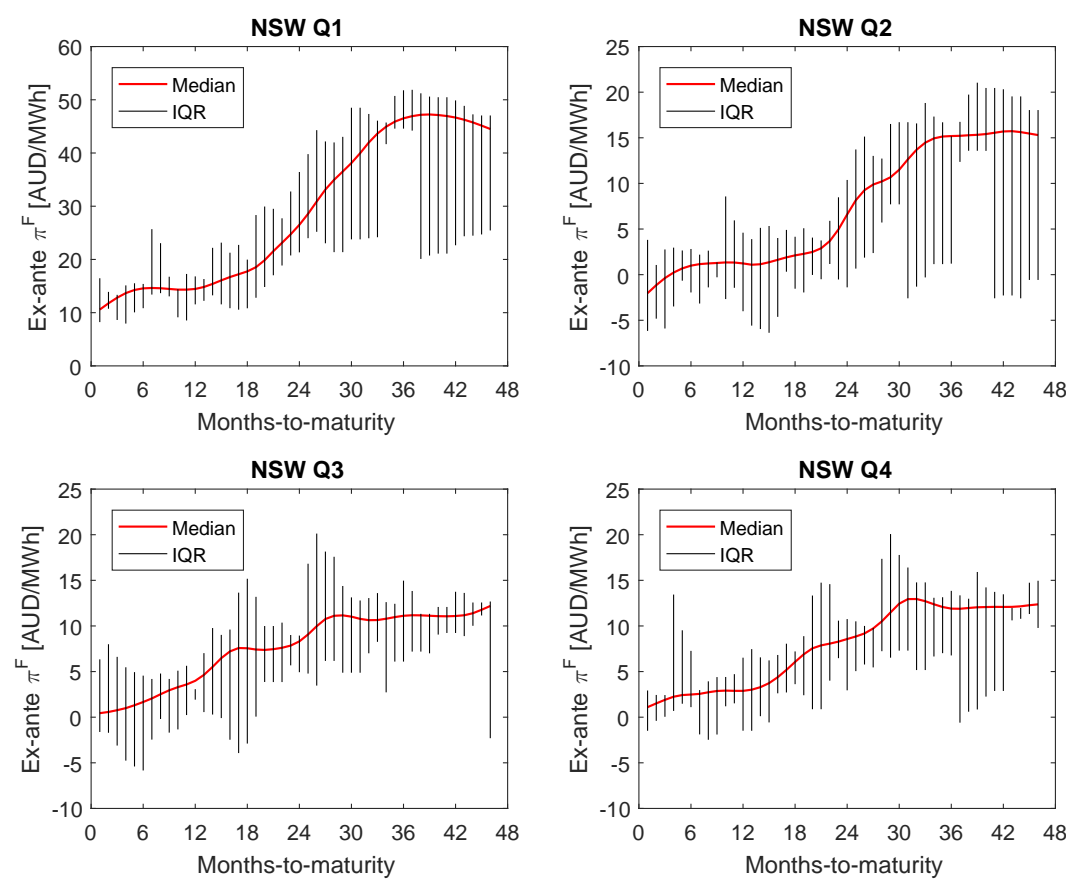

Figure 3: Smoothed ex-ante median forward risk premiums, $\pi^{F}$, for Q1 (upper left panel), Q2 (upper right panel), Q3 (lower left panel) and Q4 (lower right panel) contracts for the NSW market in the period 1 April 2008 - 31 March 2011. The vertical bars indicate the interquartile (IQR) range for each month-to-maturity.
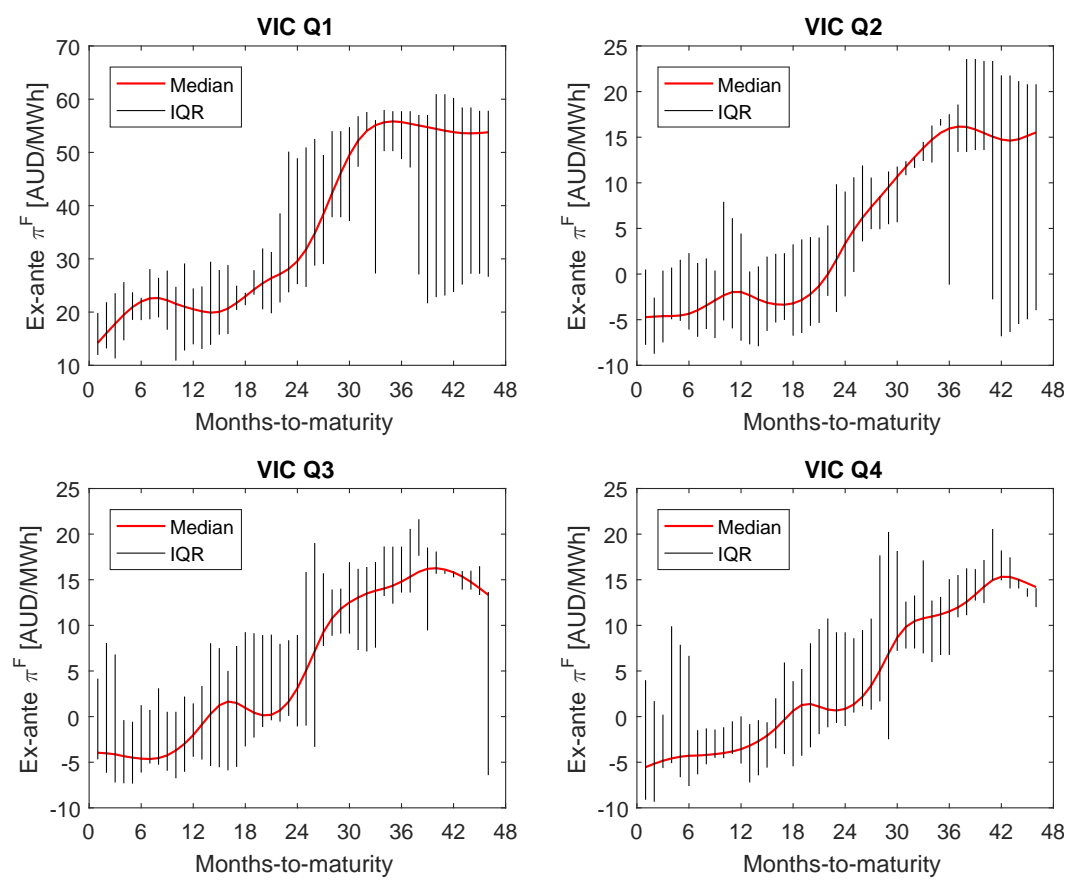

Figure 4: Smoothed ex-ante median forward risk premiums, $\pi^{F}$, for Q1 (upper left panel), Q2 (upper right panel), Q3 (lower left panel) and Q4 (lower right panel) contracts for the VIC market in the period 1 April 2008 - 31 March 2011. The vertical bars indicate the interquartile (IQR) range for each month-to-maturity. 
Table 4: Estimated market implied carbon premiums, i.e., $\pi_{t,\left[T_{1}, T_{2}\right]}^{C}$, at seven time points ranging from 1 April 2011 to 1 April 2014 for available futures contracts from Q2 2011 to Q4 2015. Results are reported for the NSW market. The tax only became effective for Q3 2012, and was abolished in Q3 2014.

\begin{tabular}{lrrrrrrr}
\hline Contract & 1.04 .2011 & 3.10 .2011 & 2.04 .2012 & 1.10 .2012 & 2.04 .2013 & 1.10 .2013 & 1.04 .2014 \\
\hline Q2 2011 & -1.65 & & & & & & \\
Q3 2011 & -0.60 & & & & & & \\
Q4 2011 & -1.24 & -2.21 & & & & & \\
Q1 2012 & -1.62 & -2.88 & & & & & \\
Q2 2012 & -1.75 & -2.57 & -2.50 & & & & \\
\hline Q3 2012 & 2.60 & 15.16 & 21.80 & & & & \\
Q4 2012 & 3.71 & 13.76 & 20.23 & 26.19 & & & \\
Q1 2013 & -0.08 & 12.24 & 16.11 & 19.58 & & & \\
Q2 2013 & 2.38 & 14.02 & 19.61 & 17.90 & 26.56 & & \\
Q3 2013 & 0.28 & 10.80 & 16.71 & 19.47 & 25.56 & & \\
Q4 2013 & -1.43 & 10.66 & 16.35 & 18.83 & 23.70 & 21.48 & \\
Q1 2014 & 6.09 & 15.67 & 9.68 & 15.48 & 17.35 & 15.04 & \\
Q2 2014 & 5.30 & 7.84 & 13.42 & 21.49 & 24.65 & 25.49 & 22.66 \\
\hline Q3 2014 & 2.22 & 0.73 & 11.75 & 14.51 & 12.27 & 15.51 & 9.92 \\
Q4 2014 & 1.75 & 1.07 & 8.54 & 14.51 & 12.65 & 12.18 & 4.32 \\
Q1 2015 & 6.29 & 2.39 & 6.97 & -7.06 & 3.44 & 1.59 & -5.54 \\
Q2 2015 & & 3.27 & 3.43 & 5.08 & 9.04 & 10.70 & 5.61 \\
Q3 2015 & & 0.08 & 2.07 & 0.64 & 2.53 & 5.92 & -0.47 \\
Q4 2015 & & & 2.59 & -1.85 & 0.89 & 4.27 & -0.90 \\
\hline
\end{tabular}

premium $\pi_{t,\left[T_{1}, T_{2}\right]}^{C}$.

In Table 4 , we provide the estimated market implied carbon premiums at seven different points in time, starting in April 2011 and ending in April 2014. The corresponding estimates for the implied carbon premiums for the other three markets QLD, SA and VIC are reported in the Appendix in Tables 5, 6 and 7, respectively. Our results suggest that in particular for April 2011 but also for October 2011, carbon premiums are typically much lower than the expected cost increase due to the tax. For the NSW market, the estimated average carbon premium for Q3 2012 - Q2 2014 contracts on 1 April 2011 was only $\$ 2.36$, while on 1 October 2011 it was as high as $\$ 12.52$. This makes perfect sense, given that in these six months details on the intended CPM were confirmed by the Labor government and the introduction and first reading of the Bill had already been held at the House of Representatives. So by October 2011, the market had already included a carbon premium in electricity futures prices from Q3 2012 onwards. This becomes obvious, when comparing futures-implied premiums for contracts with delivery in 2011 and the first two quarters of 2012. The estimated carbon premiums for these quarters are typically close to zero, suggesting that no additional adjustment for a carbon price had occurred.

\subsection{Pass-Through Rates}

With regards to the magnitude of the expected pass-through costs of the carbon tax, recall that following Nazifi (2016), we define the carbon pass-through rate as the ratio of change in the price of electricity to the change in marginal costs due to the carbon tax. Effectively we can think of 
it as the proportion of higher costs incurred by consumers in the form of higher electricity prices attributable to the carbon tax (Nelson et al., 2012; Sijm et al., 2012; Huisman and Kilic, 2015). We find that by October 2011, our estimated premiums would only suggest a price increase of ca. $55 \%$ of the expected additional costs based on emission intensities for NSW. This estimate is computed as the ratio of the mean carbon premium for futures contracts expiring in the carbon tax period (i.e., Q3 2012 to Q2 2014; see Table 4) to the mean emission intensity for NSW (see Table 3):

$$
\frac{\frac{1}{8}(15.16+13.76+12.24+14.02+10.80+10.66+15.67+7.84)}{\frac{1}{3}(21.71+22.80+23.98)}=\frac{12.52}{22.83} \approx 55 \% .
$$

A possible explanation for these results is that the Bill had not passed the House of Representatives and the Senate yet.

Considering our results for 2 April 2012 and 1 October 2012, we find that carbon premiums for Q3 2012 - Q2 2014 futures contracts had further increased on these dates. At this stage, market quotes for futures contracts clearly included a significant portion of emission intensity based additional cost estimates. Our results would suggest expected pass-through rates of ca. 75\% for 2 April 2012 and ca. 85\% for 2 October 2012. Interesting results can also be observed for the Q3 2014 - Q4 2015 contracts on 2 April 2012. There is a clear tendency for a decline in futures implied premiums for contracts with later delivery periods: while for the Q3 2014 contract, we still observe an estimated carbon premium of $\$ 11.75$, for the contracts referring to Q3 and Q4 2015 futures-implied premiums are less than $\$ 3$ based on our approach. Similar results can be observed on 2 October 2012: for Q3 and Q4 2014 contracts, premiums are still estimated to be greater than \$14, while for Q3 and Q4 2015 contracts, we observe premiums around zero. These results most likely indicate market expectations on a possible repeal of the tax or at least a significantly lower price of carbon once an Australian emissions trading scheme was in place.

Our results for carbon premiums change again, when considering the dates of 2 April 2013, 1 October 2013 and 1 April 2014. While carbon premiums for Q2 2013 - Q2 2014 contracts, the period when the tax was actually effective, are typically greater than $\$ 20$ (suggesting expected pass-through rates of ca. $95 \%$ ), we observe a very different picture for contracts with delivery from Q3 2014 onwards. In April 2013, the Liberal/National coalition had a lead in the opinion polls and had promised to abolish the tax in case they were elected. We observe that this information is clearly reflected in the futures prices for contracts with longer maturities: on 2 April 2013 average carbon premiums for these contracts are only $\$ 6.80$. Interestingly, even on 1 October 2013, i.e., after the election that had been won by the Liberal/National coalition, we still find positive carbon premiums for contracts with delivery in the post-tax period. This might still reflect some uncertainty about what was going to happen to the CPM in the near future even after the September 2013 election. However, in April 2014 market-implied carbon premiums for post-Q2 2014 contracts had dropped significantly, indicating that prices now reflected a strong belief in the abolishment of the tax by July 2014.

For the other regional markets we find a similar behavior with regards to the dynamics of initially increasing and later decreasing carbon premiums, see Tables 5.7. Premiums and passthrough rates for Q2 2013 - Q2 2014 contracts were typically very low on 1 April 2011 and 
then increased significantly until 2 April 2013. At the same time, for contracts with delivery after the actual tax period, i.e., Q3 2014 - Q4 2015, estimated carbon premiums were always of significantly lower magnitude and typically approached values below $\$ 10$ once it became clear that the tax would be abolished by the new government.

However, we can also observe some less expected results with regards to the pass-through rates in these markets. For VIC, namely the market with the highest emission intensity of approximately $1.20 \mathrm{tCO}_{2} \mathrm{e} / \mathrm{MWh}$ (see Table 3), we find that the futures-implied expected price increase for contracts with delivery during the carbon tax period was not as substantial as suggested by emission intensities. For the dates from 1 October 2012 to 1 April 2014 we observe forward-looking average carbon premiums of ca. $\$ 20$, i.e., expected carbon pass-through rates of only $65 \%$. This suggests overall significantly lower pass-through for VIC than for NSW. On the same dates, for QLD (emission intensities of ca. $0.83 \mathrm{tCO}_{2} \mathrm{e} / \mathrm{MWh}$ ) we find average forward-looking carbon premiums of ca. $\$ 27$ for contracts with delivery during the tax period, while for SA (the market with the lowest emission intensity of ca. $0.55 \mathrm{tCO}_{2} \mathrm{e} / \mathrm{MWh}$ ) the average expected carbon premium is almost \$22. These figures relate to expected average pass-through rates of $133 \%$ for QLD and $142 \%$ for SA, based on futures quotes for contracts with delivery during the tax period. Therefore, our results suggest that expected carbon pass-through rates seemed to be inversely related to emission intensities and were relatively low for the market with the highest emission intensity (VIC), while they were the highest for the market with the lowest emission intensities (SA). At the same time, expected pass-through rates seemed to be positively related to average price levels, since VIC typically exhibited the lowest wholesale prices during the sample period, and SA the highest price levels.

\subsection{The Dynamics of Carbon Premiums}

To further investigate the dynamic process of carbon premiums, in Figure 5 we plot the marketimplied carbon premiums extracted from three futures contracts: Q4 2012 from 1 October 2010 to 27 September 2012, Q3 2013 from 1 July 2011 to 28 June 2013, and Q4 2014 from 1 October 2012 to 26 September 2014. Note that for each contract a two-year time frame before the beginning of the delivery period is examined.

For the Q4 2012 futures contract (upper panel in Fig. 5) we observe a clear upward trend in the carbon premium from around zero up to nearly $\$ 28$ just before the beginning of the delivery period. In 2010 the Labor government had brought forward the notion of introducing a CPM, however had not proposed the Clean Energy Act yet. According to our results the Q4 2012 futures contract does not indicate a mark-up for this tax before April 2011. However, between April 2011 and November 2011 we find a continuous increase in the carbon premium from around $\$ 4$ up to a level of almost $\$ 20$. Interestingly, we find a second period of increase in the premium up to $\$ 28$ once the tax became effective in July 2012. This may also be a result of an increase in wholesale spot electricity prices in NSW during Q3 2012 that was actually far higher than the emission intensity based estimate of $\$ 22$.

The Q3 2013 contract (middle panel in Fig. 5) shows a very different pattern. Note that the contract was hardly traded between July and September 2011 such that the implied carbon premium remains relatively constant for this period. However, given that the notion of a CPM had been published by the government already, we observe a carbon premium of ca. $\$ 10$ for this time 

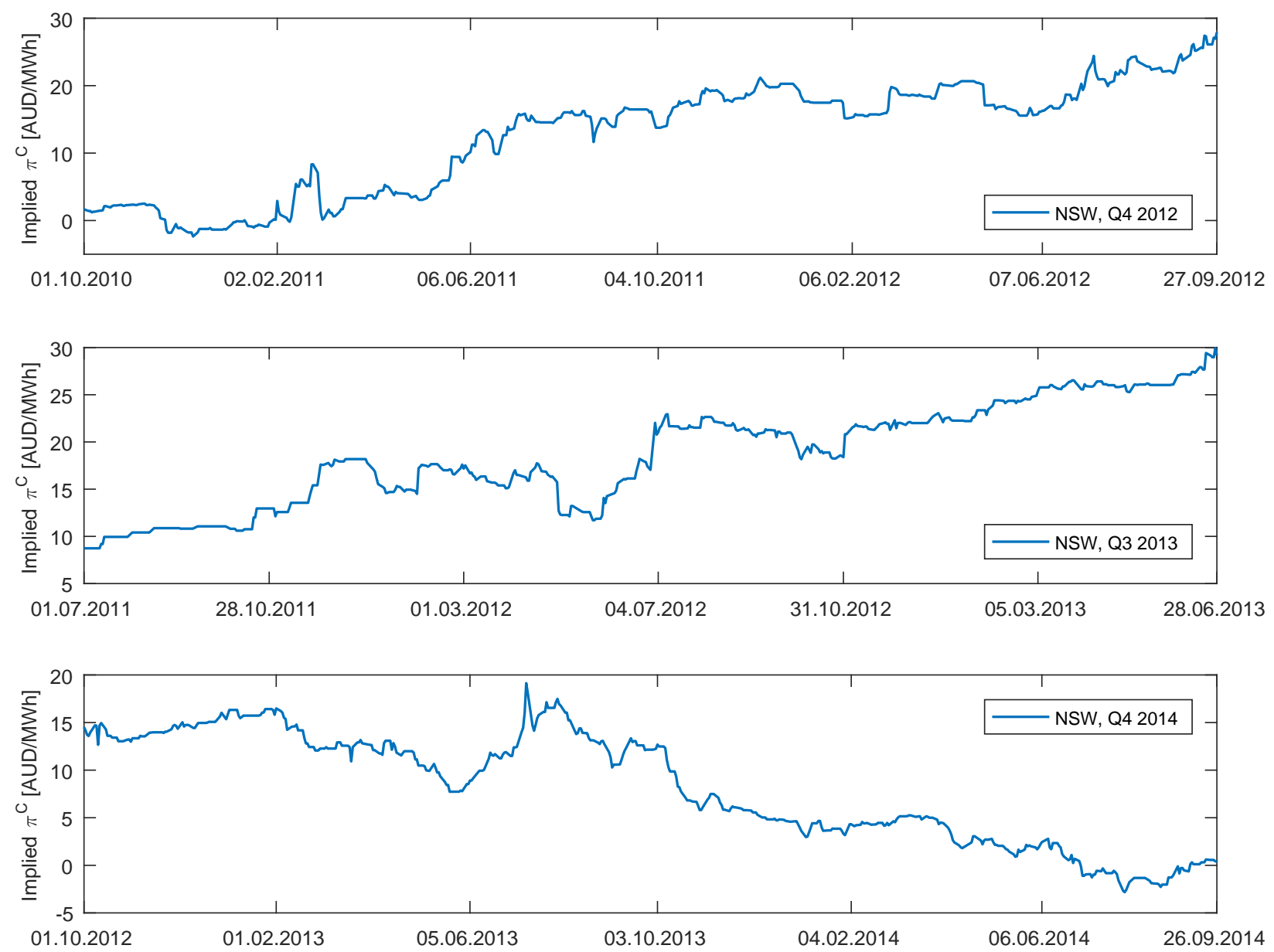

Figure 5: Implied carbon risk premium for Q4 2012 futures contract from 1 October 2010 to 27 September 2012 (upper panel), Q3 2013 futures contract from 1 July 2011 to 28 June 2013 (middle panel) and Q4 2014 futures contract from 1 October 2012 to 26 September 2014 (lower panel) for the NSW market.

period. In October-November 2011 the implied carbon premium hikes to $\$ 18$, once the bill passes the Lower and the Upper house. Interestingly, after this event, the premium drops to a level of \$15 in late January 2012 and then to \$12 in May 2012. However, similar to the Q4 2012 contract, once the tax became effective in July 2012 and spot prices in NSW increased substantially, also the carbon premium rose back to a level of almost $\$ 23$, more or less reflecting the expected additional costs based on the emission intensities for the NSW market, see Table 3 .

Now let us consider the lower panel in Figure 5 that refers to the contract with maturity in December 2014. Implied carbon premiums for this contract are particularly interesting, since they may be driven by expectations about the outcome of the federal election in September 2013. From the beginning of 2013, opinion polls drifted towards a majority for the Liberal/National coalition that had promised to abolish the tax once they were elected, see the top panel in Fig. 6 . Interestingly, the controversial carbon tax was actually one of the key topics determining the election campaign of the Liberal/National coalition. By 22 June 2013, opinion polls suggested that $42 \%$ would vote for the Labor party, while $58 \%$ preferred the Coalition to take over the 

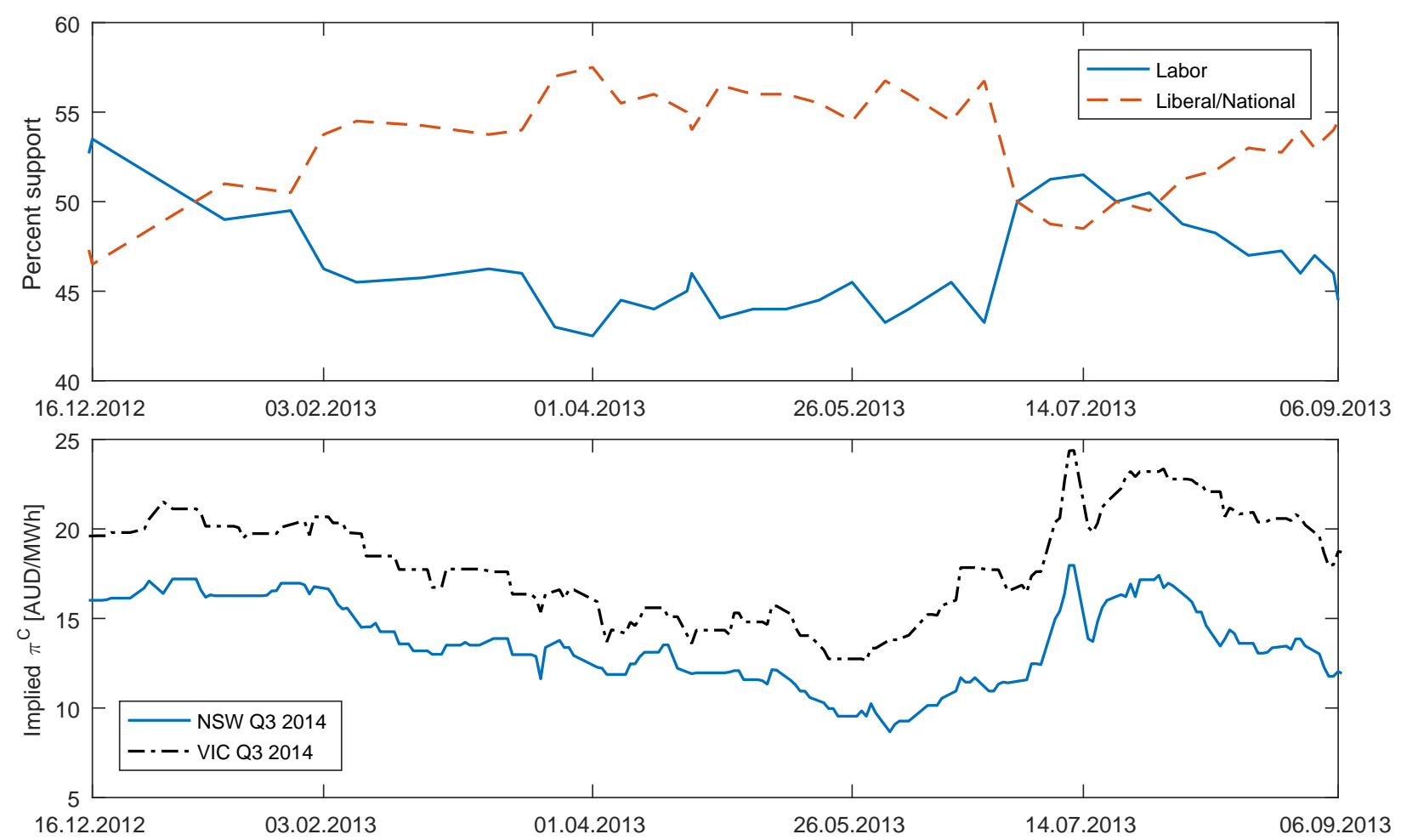

Figure 6: Results for opinion polls (upper panel) and implied carbon risk premiums, $\pi^{C}$, for Q3 2014 futures contracts in NSW and VIC (lower panel) for the time period 16 December 2012 - 6 September 2013. Note that the implied carbon risk premiums to a large extent mimic the support for the then ruling government (i.e., the Labor party).

government. This tendency is also clearly reflected in the dynamics of the carbon premium. From an initial value of $\$ 15$, the premium drops continuously to a level of ca. $\$ 7-8$ by early June.

In a last effort to turn the polls, on 26 June 2013 the Labor party decided to replace Prime Minister Gillard with former Labor Prime Minister Kevin Rudd, since it was believed that Rudd had a much better chance to win the election for the Labor party. Opinion polls suggested a possible swing towards Labor with a preference of 48\% Labor vs. 52\% Coalition on 27 June 2013 and even 51\% Labor vs. 49\% Coalition on 5 July 2013. However, in the end, the swing did not last very long and Labor lost the election on 7 September 2013. The new Coalition government then decided to abolish the Carbon Tax with the effect of Q3 2014.

The political situation, i.e., the probability of an abolishment of the tax (Coalition) against a continuation of the scheme also in 2014-2015 (Labor), is clearly reflected in the carbon premium dynamics for the Q3 2014 contract. As illustrated in Figure 6, once the opinion polls started to change during the second half of June 2013, also the implied premium increased again up to a level of \$15-18. However, when it became clear that most likely the Labor government would be replaced, the premium quickly dropped back to a level of ca. $\$ 12$; the dynamics of the carbon premiums in VIC was nearly identical, only the levels were \$3-5 higher. After the election, starting in October 2013, we see another rather rapid decline to a level of below $\$ 5$ in NSW, see the lower panel in Fig. 5. Finally, from then on the premium keeps declining until it reaches a value very close to zero just before the delivery period of the contract. 


\section{Conclusions and Policy Implications}

In this paper we have examined carbon premiums and pass-through rates in the Australian National Electricity Market (NEM) during the pre-tax, carbon tax (July 2012 - July 2014) and post-tax periods. We have developed a novel framework which consists of computing ex-ante forward risk premiums in the pre-tax period using state-of-the-art econometric techniques for modeling and forecasting electricity spot prices (Hodrick-Prescott filter based trend-seasonal pattern, Markov regime-switching driven stochastic component), then using them to derive market-implied carbon premiums in the carbon tax and post-tax periods.

We have found the obtained term structures of the forward premiums to be increasing with time to maturity: initially $\$ 10-20$ (for the first, most spiky quarter of the year) or close to zero (for quarters 2-4), then increasing respectively to $\$ 45-55$ or $\$ 10-15$ for distant maturities (third and fourth year). Interestingly, these results resemble the findings for the Nord Pool market, but contradict the results for the German EEX market where the term structure was rather downward sloping with time to maturity. Apparently, the forward premium may exhibit different dynamics depending on the characteristics of the market and the behavior of market participants.

Using futures prices instead of spot prices has allowed us to take a forward-looking approach, and to thoroughly examine the impact of key policy events on observed carbon premiums in the electricity markets. Hereby, we have analyzed the impact of announcements about the introduction of the tax, opinion polls on upcoming federal election, as well as the actual change of the federal government that was accompanied by the promise to repeal the tax. Our results clearly indicate the impact of political news on the carbon premiums. We find that the market reacted relatively quickly to the passing of the Clean Energy Bill by the Labor government in July 2011. Even more striking is the inclusion of news about opinion polls for the 2013 Australian federal election with regards to the existing Labor government vs. the Liberal/National opposition.

Finally, having derived the carbon premiums and given the approximate emission intensities of generation in the considered regional markets, we have been able to compute carbon pass-through rates. During the period where market participants could be relatively certain that the tax would be effective, we have found expected carbon pass-through rates to be between $65 \%$ and $140 \%$. Interestingly, they seem to be inversely related to emission intensities - they are relatively low for the market with the highest emission intensity (VIC) and the highest for the market with the lowest emission intensities (SA). At the same time, they seem to be positively related to average price levels, since VIC typically exhibited the lowest wholesale prices during the sample period, and SA the highest price levels. Our results also indicate that for all four markets futures prices typically increased by a relatively similar margin. This would suggest that the observed mark-up did not necessarily take into account actual emission intensities, but was rather based on overall expectations of a common shock (of similar magnitude) to wholesale electricity prices in the NEM. Naturally, under such a scenario, markets with high emission intensities (such as VIC) will have lower pass-through rates, while markets with a higher share of clean energy and significantly lower emission intensities (such as SA) will indicate the highest pass-through rates.

Our findings also provide important policy implications with regards to the impact of the CPM on the Australian wholesale electricity market. First, our results indicate that the carbon tax has only resulted in a relatively small reduction of emission intensities, while it has led to a significant 
increase in (expectations about) electricity prices. From this angle one could argue that the scheme was not particularly effective in reducing carbon emissions at a low cost. Based on our findings, it is also questionable whether the carbon tax has led to a substantial and long-lasting change in the mix of electricity generation for the considered markets. At least for two of the markets (NSW and QLD), after the abolishment of the tax emission intensities reverted back to their pre-tax levels.

Combined, these findings would suggest that instead of executing a significant change in their generation fuel mix, generators rather decided to simply pass on the additional costs of generation to consumers. The observed average pass-through rates of 133\% for QLD and 142\% for SA would also suggest that this pass-through was even done at a higher level than expected based on emission intensities and the costs of carbon per MWh of electricity generation. These findings also raise the question of potential 'windfall profits' for generators in these markets.

Finally, our results on continuous changes in observed carbon premiums are also a clear indication of policy uncertainty with regards to the CPM. While the market reacted relatively quickly to news about the carbon tax, the ever-changing level of the premiums throughout the sample period is clearly a result of constantly revised expectations about the continuation of the carbon pricing mechanism. As a result of this uncertainty, the impact of the CPM on investment into 'greener' generation assets has been rather limited, what is also confirmed by the observed emission intensities. One could argue that the CPM has resulted mainly in short-term and minor changes in generation behavior, since it was not considered to remain in place over relevant investment horizons. Therefore, a key implication for regulators and policy makers is that in the future a stable and long-term policy framework would be required for a carbon pricing mechanism to have its full effect.

\section{Acknowledgements}

This paper has benefited from conversations with the participants of the Conference on Energy Finance (EF2016), the Energy Finance Christmas Workshops (EFC15, EFC16), the Modern Electric Power Systems Symposium (MEPS15), as well as seminars at University of New South Wales and University of Technology Sydney. This work was partially supported by the Ministry of Science and Higher Education (MNiSW, Poland) grant no. 0178/DIA/2012/41 (to PM), the Australian Research Council through grant no. DP1096326 (to ST and RW) and the National Science Center (NCN, Poland) grant no. 2015/17/B/HS4/00334 (to RW).

\section{Bibliography}

Apergis, N., Lau, M. C. K., 2015. Structural breaks and electricity prices: Further evidence on the role of climate policy uncertainties in the Australian electricity market. Energy Economics 52, Part A, 176 - 182.

Australian Treasury, 2011. Strong growth, low pollution, modelling a carbon price. Tech. rep.

Benth, F., Biegler-König, R., Kiesel, R., 2013. An empirical study of the information premium on electricity markets. Energy Economics 36, 55-77.

Benth, F., Cartea, A., Kiesel, R., 2008. Pricing forward contracts in power markets by the certainty equivalence principle: Explaining the sign of the market risk premium. Journal of Banking and Finance 32 (10), 2006-2021.

Bessembinder, H., Lemmon, M., 2002. Equilibrium pricing and optimal hedging in electricity forward markets. Journal of Finance 57, 1347-1382. 
Bierbrauer, M., Menn, C., Rachev, S.T., Trück, S., 2007. Spot and derivative pricing in the EEX power market. Journal of Banking and Finance 31(11), 3462-3485.

Blyth, W., Bunn, D., 2011. Coevolution of policy, market and technical price risks in the EU ETS. Energy Policy 39 (8), 4578-4593.

Botterud, A., Kristiansen, T., Ilic, M., 2010. The relationship between spot and futures prices in the Nord Pool electricity market. Energy Economics 32(5), 967-978.

Bunn, D., Chen, D., 2013. The forward premium in electricity futures. Journal of Empirical Finance 23, $173-186$.

Bunn, D., Fezzi, C., 2009. Structural interactions of European carbon trading and energy prices. The Journal of Energy Markets 2 (4), 53-69.

Chevallier, J., 2011. Econometric analysis of carbon markets: the European Union emissions trading scheme and the clean development mechanism. Springer Science \& Business Media.

Clean Energy Regulator, 2013. Carbon pricing mechanism. Australian Government Clean Energy Regulator Publication.

Clements, A., Herrera, R., Hurn, A., 2015. Modelling interregional links in electricity price spikes. Energy Economics 51, 383-393.

Daskalakis, G., Markellos, R., 2009. Are electricity risk premia affected by emission allowance prices? Evidence from the EEX, Nord Pool and Powernext. Energy Policy 37, 2594-2604.

Eichler, M., Türk, D., 2013. Fitting semiparametric markov regime-switching models to electricity spot prices. Energy Economics 36, 614-624.

Fell, H., 2010. EU-ETS and Nordic electricity: A CVAR analysis. The Energy Journal 31 (2), 1-25.

Garnaut, R., 2008. The Garnaut climate change review. Cambridge.

Gronwald, M., Ketterer, J., Trück, S., 2011. The relationship between carbon, commodity and financial markets: A copula analysis. Economic Record 87.

Gulli, F., Chernyavska, L., 2013. Theory and empirical evidence for carbon cost pass-through to energy prices. Annual Review of Resource Economics 5, 349-367.

Handika, R., Trück, S., 2014a. The dynamics of risk premiums in Australian electricity futures markets. Tech. rep.

Handika, R., Trück, S., 2014b. Risk premiums in interconnected Australian electricity futures markets. Tech. rep.

Haugom, E., Hoff, G. A., Mortensen, M., Molnar, P., Westgaard, S., 2014. The forecasting power of medium-term futures contracts. Journal of Energy Markets 7 (4), 47-69.

Haugom, E., Ullrich, C. J., 2012. Market efficiency and risk premia in short-term forward prices. Energy Economics 34 (6), 1931-1941.

Hirschhausen, v. C., Zachmann, G., 2008. First evidence of asymmetric cost pass-through of EU emissions allowances: Examining wholesale electricity prices in Germany. Economic Letters 99 (3), 465-469.

Hodrick, R. J., Prescott, E. C., 1997. Postwar U.S. business cycles: An empirical investigation. Journal of Money, Credit and Banking 29 (1), 1-16.

Huisman, R., Kilic, M., 2012. Electricity futures prices: Indirect storability, expectations, and risk premiums. Energy Economics 34 (4), 892-898.

Huisman, R., Kilic, M., 2015. Time variation in European carbon pass-through rates in electricity futures prices. Energy Policy 86, 239-249.

Ignatieva, K., Trück, S., 2016. Modeling spot price dependence in Australian electricity markets with applications to risk management. Computers \& Operations Research 66, 415-433.

International Energy Agency, 2010. IEA World Energy Outlook. Tech. rep.

Janczura, J., 2014. Pricing electricity derivatives within a markov regime-switching model: A risk premium approach. Mathematical Methods of Operations Research 79 (1), 1-30.

Janczura, J., Trück, S., Weron, R., Wolff, R., 2013. Identifying spikes and seasonal components in electricity spot price data: A guide to robust modeling. Energy Economics 38, 96-110.

Janczura, J., Weron, R., 2010. An empirical comparison of alternate regime-switching models for electricity spot prices. Energy Economics 32(5), 1059-1073.

Janczura, J., Weron, R., 2012. Efficient estimation of markov regime-switching models: An application to electricity spot prices. AStA - Advances in Statistical Analysis 96(3), 385-407.

Jouvet, P.-A., Solier, B., 2013. An overview of $\mathrm{CO}_{2}$ cost pass-through to electricity prices in Europe. Energy Policy 
61, 1370-1376.

Kanamura, T., 2015. Dynamic price linkage and volatility structure model between carbon markets. Springer Proceedings in Mathematics and Statistics 122, 301-308.

Kanamura, T., 2016. Role of carbon swap trading and energy prices in price correlations and volatilities between carbon markets. Energy Economics 54, 204-212.

Karakatsani, N., Bunn, D., 2010. Fundamental and behavioural drivers of electricity price volatility. Studies in Nonlinear Dynamics and Econometrics 14 (4), 4.

Liebl, D., 2013. Modeling and forecasting electricity spot prices: A functional data perspective. Annals of Applied Statistics 7 (3), 1562-1592.

Lisi, F., Nan, F., 2014. Component estimation for electricity prices: Procedures and comparisons. Energy Economics 44, 143-159.

Longstaff, F., Wang, A., 2004. Electricity forward prices: A high-frequency empirical analysis. Journal of Finance 59, 1877-1900.

McLennan Magasanik Associates, 2008. Impacts of the carbon pollution reduction scheme on generator profitability. MMA Publication, Melbourne.

Nazifi, F., 2013. Modelling the price spread between EUA and CER carbon prices. Energy Policy 56, 434-445.

Nazifi, F., 2016. The pass-through rates of carbon costs on to electricity prices within the Australian National Electricity Market. Environmental Economics and Policy Studies 18 (1), 41-62.

Nazifi, F., Milunovich, G., 2010. Measuring the impact of carbon allowance trading on energy prices. Energy and Environment 21 (5), 367-383.

Nelson, T., Kelley, S., Orton, F., 2012. A literature review of economic studies on carbon pricing and Australian wholesale electricity markets. Energy Policy 49, 217-224.

Nowotarski, J., Tomczyk, J., Weron, R., 2013. Robust estimation and forecasting of the long-term seasonal component of electricity spot prices. Energy Economics 39, $13-27$.

O’Gorman, M., Jotzo, F., 2014. Impact of the carbon price on Australia's electricity demand, supply and emissions. Working paper.

Redl, C., Haas, R., Huber, C., Böhm, B., 2009. Price formation in electricity forward markets and the relevance of systematic forecast errors. Energy Economics 31 (3), 356-364.

ROAM, 2008. Modeling of carbon pricing scenarios. ROAM Consulting Publication, Brisbane.

Sijm, J., Chen, Y., Hobbs, B. F., 2012. The impact of power market structure on CO2 cost pass-through to electricity prices under quantity competition - A theoretical approach. Energy Economics 34 (4), 1143-1152.

Sijm, J., Neuhoff, K., Chen, Y., 2006. CO2 cost pass-through and windfall profits in the power sector. Climate Policy $6(1), 49-72$.

Simshauser, P., Doan, T., 2009. Emissions trading, wealth transfers and the wounded bull scenario in power generation. Australian Economic Review 42 (1), 64-83.

Weron, R., 2006. Modeling and Forecasting Electricity Loads and Prices: A Statistical Approach. Wiley, Chichester.

Weron, R., 2008. Market price of risk implied by Asian-style electricity options and futures. Energy Economics 30, 1098-1115.

Weron, R., 2014. Electricity price forecasting: A review of the state-of-the-art with a look into the future. International Journal of Forecasting 30 (4), 1030-1081.

Weron, R., Zator, M., 2014. Revisiting the relationship between spot and futures prices in the Nord Pool electricity market. Energy Economics 44, 178-190.

Weron, R., Zator, M., 2015. A note on using the Hodrick-Prescott filter in electricity markets. Energy Economics 48, $1-6$. 


\section{Appendix: Observed Carbon Premiums in the States of QLD, SA and VIC}

Table 5: Estimated market implied carbon premiums, i.e., $\pi_{t,\left[T_{1}, T_{2}\right]}^{C}=F_{t,\left[T_{1}, T_{2}\right]}-\left\{E\left(\bar{S}_{\left[T_{1}, T_{2}\right]}\right)+\pi_{t,\left[T_{1}, T_{2}\right]}^{F}\right\}$, at seven time points ranging from 1 April 2011 to 1 April 2014 for available futures contracts from Q2 2011 to Q4 2015. Results are reported for the QLD market. The tax only became effective for Q3 2012, and was abolished in Q3 2014.

\begin{tabular}{rrrrrrrr}
\hline Contract & 1.04 .2011 & 3.10 .2011 & 2.04 .2012 & 1.10 .2012 & 2.04 .2013 & 1.10 .2013 & 1.04 .2014 \\
\hline Q2 2011 & -0.12 & & & & & & \\
Q3 2011 & -0.02 & & & & & & \\
Q3 2011 & -2.49 & -0.75 & & & & & \\
Q1 2012 & -2.44 & -2.60 & & & & & \\
Q2 2011 & 0.81 & 4.00 & 3.23 & & & & \\
\hline Q3 2012 & 4.05 & 21.03 & 24.32 & & & & \\
Q4 2012 & 1.49 & 18.61 & 20.28 & 32.77 & & & \\
Q1 2013 & 1.75 & 18.50 & 19.73 & 26.16 & & & \\
Q2 2013 & 7.06 & 21.20 & 24.13 & 30.09 & 26.32 & & \\
Q3 2013 & 4.23 & 19.25 & 21.53 & 30.60 & 31.63 & & \\
Q4 2013 & 0.69 & 17.08 & 18.13 & 26.07 & 25.45 & 32.05 & \\
Q1 2014 & 7.51 & 22.05 & 14.34 & 25.54 & 21.19 & 26.93 & \\
Q2 2014 & 8.13 & 10.09 & 13.46 & 29.28 & 27.46 & 32.64 & 21.56 \\
\hline Q3 2014 & 1.70 & 4.35 & 15.8 & 22.29 & 18.80 & 22.06 & 11.29 \\
Q4 2014 & 2.05 & 3.86 & 10.20 & 18.73 & 14.08 & 18.66 & 7.71 \\
Q1 2015 & 7.72 & 9.16 & 19.93 & 3.10 & 6.54 & 16.47 & 7.27 \\
Q2 2015 & & 9.60 & 15.56 & 8.94 & 10.44 & 18.68 & 11.05 \\
Q3 2015 & & 4.98 & 7.35 & 2.87 & 5.15 & 13.96 & 6.37 \\
Q4 2015 & & & 8.36 & 2.44 & 2.02 & 10.70 & 4.19 \\
\hline
\end{tabular}


Table 6: Estimated market implied carbon premiums, i.e., $\pi_{t,\left[T_{1}, T_{2}\right]}^{C}=F_{t,\left[T_{1}, T_{2}\right]}-\left\{E\left(\bar{S}_{\left[T_{1}, T_{2}\right]}\right)+\pi_{t,\left[T_{1}, T_{2}\right]}^{F}\right.$, at seven time points ranging from 1 April 2011 to 1 April 2014 for available futures contracts from Q2 2011 to Q4 2015. Results are reported for the SA market. The tax only became effective for Q3 2012, and was abolished in Q3 2014.

\begin{tabular}{lrrrrrrr}
\hline Contract & 1.04 .2011 & 3.10 .2011 & 2.04 .2012 & 1.10 .2012 & 2.04 .2013 & 1.10 .2013 & 1.04 .2014 \\
\hline Q2 2011 & 1.12 & & & & & & \\
Q3 2011 & -3.93 & & & & & & \\
Q4 2011 & -7.91 & -16.04 & & & & & \\
Q1 2012 & -16.84 & -13.56 & & & & & \\
Q2 2012 & -6.56 & -2.13 & -15.09 & & & & \\
\hline Q3 2012 & -10.49 & 14.27 & 14.27 & & & & \\
Q4 2012 & -5.48 & 15.30 & 13.49 & 4.20 & & & \\
Q1 2013 & 0.54 & -0.43 & 0.40 & -9.78 & & & \\
Q2 2013 & 9.47 & 17.10 & 17.23 & 30.35 & 38.22 & & \\
Q3 2013 & 10.45 & 1.99 & 7.91 & 31.83 & 41.66 & & \\
Q4 2013 & 8.84 & -3.75 & 5.74 & 9.76 & 23.17 & 2.44 & \\
Q1 2014 & 7.08 & 6.29 & 4.05 & 5.93 & 2.18 & -1.03 & \\
Q2 2014 & 7.31 & 4.14 & 2.31 & 17.58 & 39.51 & 43.38 & 29.89 \\
\hline Q3 2014 & 10.49 & 6.43 & 14.67 & 16.65 & 28.63 & 31.30 & 23.88 \\
Q4 2014 & 10.63 & 12.2 & 11.79 & 7.74 & 14.49 & 12.14 & 4.44 \\
Q1 2015 & 3.41 & 7.83 & 11.26 & 8.47 & -2.24 & 1.08 & -17.14 \\
Q2 2015 & & 8.52 & 8.64 & 16.41 & 7.38 & 22.25 & 18.12 \\
Q3 2015 & & 16.38 & 12.07 & 12.42 & 3.62 & 11.44 & 11.75 \\
Q4 2015 & & & 5.87 & 21.29 & 1.94 & 6.19 & 0.25 \\
\hline
\end{tabular}


Table 7: Estimated market implied carbon premiums, i.e., $\pi_{t,\left[T_{1}, T_{2}\right]}^{C}=F_{t,\left[T_{1}, T_{2}\right]}-\left\{E\left(\bar{S}_{\left[T_{1}, T_{2}\right]}\right)+\pi_{t,\left[T_{1}, T_{2}\right]}^{F}\right\}$, at seven time points ranging from 1 April 2011 to 1 April 2014 for available futures contracts from Q2 2011 to Q4 2015. Results are reported for the VIC market. The tax only became effective for Q3 2012, and was abolished in Q3 2014.

\begin{tabular}{lrrrrrrr}
\hline Contract & 1.04 .2011 & 3.10 .2011 & 2.04 .2012 & 1.10 .2012 & 2.04 .2013 & 1.10 .2013 & 1.04 .2014 \\
\hline Q2 2011 & 1.03 & & & & & & \\
Q3 2011 & -0.03 & & & & & & \\
Q4 2011 & -0.04 & 1.09 & & & & & \\
Q1 2012 & -9.15 & -3.79 & & & & & \\
Q2 2012 & -0.66 & 1.97 & 2.22 & & & & \\
\hline Q3 2012 & 4.01 & 19.97 & 25.37 & & & & \\
Q4 2012 & 4.57 & 19.71 & 24.56 & 29.53 & & & \\
Q1 2013 & -2.11 & 9.34 & 11.73 & 13.43 & & & \\
Q2 2013 & 0.28 & 18.52 & 22.83 & 26.97 & 26.40 & & \\
Q3 2013 & 2.19 & 17.73 & 19.32 & 27.06 & 28.32 & & \\
Q4 2013 & 0.92 & 12.17 & 19.56 & 24.19 & 27.02 & 28.20 & \\
Q1 2014 & 4.08 & 18.10 & 9.50 & 10.55 & 11.92 & 12.83 & \\
Q2 2014 & 9.32 & 14.35 & 14.84 & 25.35 & 26.38 & 31.44 & 26.51 \\
\hline Q3 2014 & 0.29 & 3.62 & 9.89 & 19.17 & 15.93 & 21.40 & 14.38 \\
Q4 2014 & -1.08 & 3.67 & 11.88 & 18.03 & 15.14 & 15.68 & 9.88 \\
Q1 2015 & 5.22 & 6.36 & 7.66 & -4.29 & -0.01 & 1.18 & -9.23 \\
Q2 2015 & & 11.79 & 12.18 & 8.42 & 12.08 & 15.27 & 7.65 \\
Q3 2015 & & 3.54 & 2.39 & -1.27 & 0.97 & 11.49 & 3.64 \\
Q4 2015 & & & 1.49 & -0.83 & 0.61 & 10.25 & 2.81 \\
\hline
\end{tabular}




\section{HSC Research Report Series 2016}

For a complete list please visit http://ideas.repec.org/s/wuu/wpaper.html

01 To combine or not to combine? Recent trends in electricity price forecasting by Jakub Nowotarski and Rafał Weron

02 The diamond model of social response within an agent-based approach by Paul R. Nail and Katarzyna Sznajd-Weron

03 Linking consumer opinions with reservation prices in an agent-based model of innovation diffusion by Anna Kowalska-Pyzalska, Karolina Ćwik, Arkadiusz Jędrzejewski and Katarzyna Sznajd-Weron

04 Impact of social interactions on demand curves for innovative products by Katarzyna Maciejowska, Arkadiusz Jędrzejewski, Anna Kowalska-Pyzalska and Rafał Weron

05 On the importance of the long-term seasonal component in day-ahead electricity price forecasting by Jakub Nowotarski and Rafał Weron

06 Automated variable selection and shrinkage for day-ahead electricity price forecasting by Bartosz Uniejewski, Jakub Nowotarski and Rafał Weron

07 Recent advances in electricity price forecasting: A review of probabilistic forecasting by Jakub Nowotarski and Rafał Weron

08 Day-ahead electricity price forecasting with high-dimensional structures: Univariate vs. multivariate models by Florian Ziel and Rafał Weron

09 What makes consumers adopt to innovative energy services in the energy market? by Anna Kowalska-Pyzalska

10 Carbon pricing, forward risk premiums and pass-through rates in Australian electricity futures markets by Paweł Maryniak, Stefan Trück and Rafał Weron 